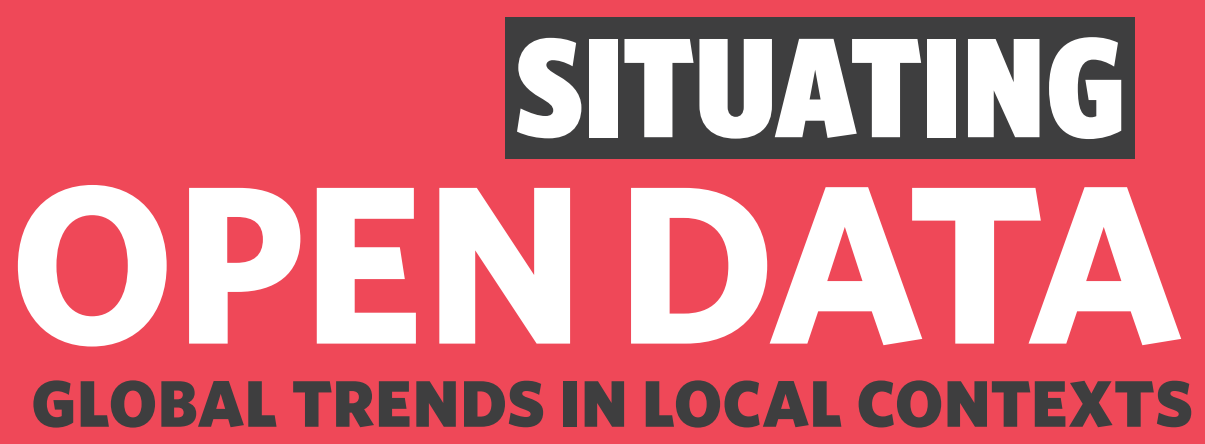

Edited by Danny Lämmerhirt, Ana Brandusescu, Natalia Domagala \& Patrick Enaholo 


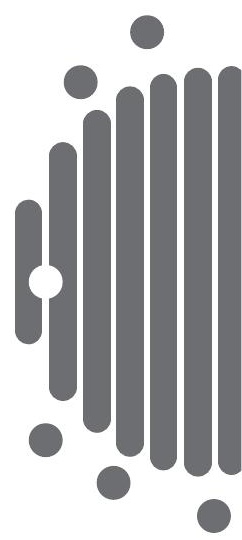

\section{Situating Open Data Global Trends in Local Contexts}

Edited by

Danny Lämmerhirt, Ana Brandusescu, Natalia Domagala \& Patrick Enaholo 
Published in 2020 by African Minds

4 Eccleston Place, Somerset West 7130, Cape Town, South Africa

info@africanminds.org.za

www.africanminds.org.za

This work is published under a Creative Commons Attribution 4.0 International License (CC-BY).

ISBN Paper 978-1-928502-12-8

ISBN eBook 978-1-928502-13-5

ISBN ePub 978-1-928502-14-2

Orders:

African Minds

4 Eccleston Place, Somerset West 7130, Cape Town, South Africa

info@africanminds.org.za

www.africanminds.org.za

For orders from outside South Africa:

African Books Collective

PO Box 721, Oxford OX1 9EN, UK

orders@africanbookscollective.com

www.africanbookscollective.com 


\title{
4. \\ Localising global commitments: Open data in sub-national contexts in Indonesia and the Philippines
}

\author{
Michael Cañares
}

The Open Government Partnership (OGP) is a multilateral initiative that aims to secure concrete commitments from governments to promote transparency, empower citizens, fight corruption, and harness new technologies to strengthen governance. OGP's vision is that governments become more transparent, accountable, and responsive to their own citizens, with the goal of improving the quality of governance, as well as the quality of services that citizens receive. Since its inception in 2011, OGP brings together 75 countries and 15 sub-national governments with over 2500 commitments to make their governments more open. Undoubtedly, the OGP is a global process with nation-states participating in its institutionalisation. In the early days of the OGP, national representatives, who are the pioneer members of the OGP, bound themselves to the ideals of transparency, accountability, citizen participation, and innovation, with the end view of improving governance and public service delivery (OGP 2016). National governments and their civil society counterparts developed national action plans to enact measures to achieve the OGP goals. Sub-national governments became a significant focus of the OGP efforts only in 2015. The move towards the 'local' is conditioned by several normative arguments proposed by the Open Government Subnational Declaration - that the government is closest to the people at the sub-national level, that the sub-national space offers greater opportunity for transformative change, and that civil society organisations can engage in better discussions with government through sub-national platforms (OGP 2016a). Based on 2015 OGP statistics, a total of 73 out of 1894 commitments to date address local issues or involve stakeholders from sub-national governments (OGP 2015). 
Localising, or the process of localisation of global agenda, has been discussed extensively within the context of environmental protection and development studies. Localisation is a paradigm that favours the local over everything else (in particular globalisation) and results in more control of processes by local actors and communities (Hines 2000). Nevertheless, it is also argued that globalisation and localisation are not competing processes and that the local is a manifestation of greater interconnectedness, hence changes at the local inform global contexts, and global pursuits affect local behaviour (Voisey \& O'Riordan 2001). In a recent paper by the Asian Development Bank (2017), it was argued that localising global agenda is not just about integrating global agenda into sub-national plans but empowering sub-national governments to implement those plans and programmes. At the same time, it is about connecting the local with wider national and global debates and how this affects local systems and processes. This reminds us of earlier arguments on globalisation (Escobar 2001), where political processes are institutionalised in one place but are invariably connected to processes beyond it. In the context of open government data, it has been argued that the local is important because, in decentralised contexts, the local is where data is collected and stored, where there is strong feasibility that data will be published, and where data can generate the most impact when used (Cañares \& Shekhar 2016). In the case of other global goals, the Sustainable Development Goals (SDGs) in particular, the role of local contexts is seen as critical in transforming global goals to local reality (UN 2014).

At the national level, several building blocks for open government have been identified by scholars. For example, Heeks (2004) argues that external pressure and internal political desire are strong drivers of e-government success and complemented by technology, strategy, design and competency, will ensure the success of e-government. In the case of open governments and writing from an analytical vantage point of transparency and accountability initiatives, Peixoto and Fox (2015) point to the nature of civic engagement as the main driver of downward accountability, and that institutional response is conditioned by willingness and capacity. Recently, in a synthesis paper on open data and sub-national governments across nine cases from six countries, Cañares and Shekhar (2016) argue that there are six facilitating factors for open data initiatives to succeed - political leadership, implementation structure, readily available governance data, technical capacity, existence of intermediaries, and implementation of concrete initiatives. The ADB synthesis paper (2017) agrees with these analyses, emphasising the importance of creating an enabling environment through a legal or policy framework for localisation, financing investments and building the capacity for all actors beyond local governments. This chapter explores to what extent the same characteristics that made open government successful at the national level will resonate in sub-national spaces.

The localisation of OGP is analysed in the context of Indonesia and the Philippines, the pioneering members of the OGP. These governments have 
launched initiatives to involve citizens in preparing, implementing and monitoring OGP National Action Plans (NAP) since 2012. Furthermore, both countries launched their open data portals as a part of their national action plans - Indonesia in 2014, and the Philippines in 2015. In 2016, Indonesia and the Philippines started to cascade OGP processes and open data initiatives to the sub-national level. This chapter would like to assess the evidence of localising open data initiatives by answering the following questions: (1) what were the drivers for localising open data commitments by local governments; (2) what challenges exist in localising global commitments on open data; (3) what recommendations can be made to enable effective implementation of open data at the sub-national level? Answers to these questions are crucial, especially in a context where the OGP intensifies its efforts to localise OGP processes in several countries, funding initiatives through a dedicated grants window supported by different donors. This chapter is structured in three parts. The first section explains the background and methodology, the second part presents findings and discussion arising from the case studies and the concluding chapter offers recommendations.

\section{Methodology}

This chapter analyses two sub-national case studies from Indonesia and the Philippines. Both countries share a similar political trajectory - they experienced authoritarian regimes and are relatively new in terms of democratisation and decentralisation (Fukuoka 2015); nevertheless, there are inherent differences in their local politics (Sidel 2005).

The case study sites of Bohol province in the Philippines and the city of Banda Aceh in Indonesia were chosen from a list of early adopters of open data initiatives. Both Bohol and Banda Aceh are parts of the current sub-national pilot of the OGP action plans of both countries. Moreover, the intention was to investigate different sub-national levels - a province and a city - the former larger in scope and involving several sub-national jurisdictions (e.g. municipalities), and the latter being a single governance entity with a significant population and a myriad of urban concerns. The research was conducted over six months from June 2017 using a primarily qualitative approach. A review of documents, including policies, relevant legislation, project documentation, and prior research papers was conducted at the beginning in order to understand the context of open data initiatives in each place. In each case, a total of 20 key informants were selected for interviews consisting of ten government actors and ten non-state actors. The intention was to gather balanced perspectives from different stakeholders. The narratives from the documents reviewed and the key informant interviews were analysed and common themes were extracted to reveal patterns, areas of agreement, and points of contention. In the analysis, the research considered three factors: (1) the political environment that conditions 
the open data initiatives; (2) the internal and external pressures that catalyse or prevent the localisation agenda; and (3) the processes that were undertaken to adapt global commitments to the local context.

\section{Findings and discussion}

This section will discuss findings from Bohol in the Philippines and Banda Aceh in Indonesia and outline the implications that the findings have on the wider question of localising the open government and open data agenda.

\section{Bohol: Operationalising full disclosure}

Bohol is situated in the centre of Visayas region between the south-eastern, Cebu and the south-western, Leyte. The island province of Bohol is the tenth largest island of the Philippines and is composed of one city, 47 municipalities and 1109 barangays. As of 2010, it has a total population of 1255 128, with 242307 households with an average household size of 5.1. The main economic sectors are agriculture, industry, fishery and tourism. The Provincial Government of Bohol is one of the stellar performers in terms of local governance and public service delivery because of a professionalised bureaucracy and a thriving civil society. Although provincial leadership is passed from one politician to another in a seemingly scheduled rotation of key political positions (e.g. the governor becomes the district representative in the next elections), the performance of local governance is largely driven by a competent set of civil servants held in regular check by active civil society organisations and local media.

This political landscape enables open government interventions to thrive. When the national government issued the guidelines for the publication of local financial accounts and other relevant information through the Full Disclosure Policy (FDP) portal, Bohol was one of the early adopters, creating an enabling mechanism to ensure compliance. Bohol was rated as fully compliant with the FDP as it published the required information. Data suppliers prepared the required documents for the disclosure and were tasked to submit the documents through a compliance monitor, the Provincial Internal Audit Office (PIAO), which works in coordination with the ICT unit to ensure that all data requirements are uploaded. Data uploading was done by the ICT unit whose main task was to look after the government IT systems and the website. Uploading documents to the website and the FDP portal is just a fraction of their total mandate.

However, although a compliance mechanism was set up inside of the local government, convening different agencies, systematising a timeline for data availability and disclosure, and assigning a central compliance agency, there was no initiative to inform and build the capacity of the users. The FDP is a part of the enabling mechanisms of a national commitment from the first OGP national 
action plan in the Philippines and has been reported as one of the important actions that contributed to the completion of the commitment (Mangahas 2014). The system has been cascaded to the local level to support transparency and information disclosure; nevertheless, no effort has been made to inform the public about the existence of the portal or its use. The good intentions of openness fell short of enabling participation (Cañares 2014).

An action research project funded by the International Development Research Centre and implemented by Step Up Consulting Services aimed to enhance citizen engagement through open government data and was implemented in 2015 to 2016 in Bohol and the neighbouring province of Dumaguete. The project was the first time when stakeholders in Bohol (advocacy groups, nongovernment organisations, and people's collectives), were trained on how to access the data from the portal, scrape the data (from PDF), convert it to a format that would allow analysis (e.g. CSV, or comma-separated values), and use the data and its corresponding analysis to ask government certain questions, demand explanation, and initiate dialogue on key issues of their interest (Cañares et al. 2016).

Before the training, only one out of the 21 organisations surveyed had accessed and seen documents uploaded onto the FDP portal. The majority of them accessed government data through formal (e.g. writing a letter) or informal means (e.g. asking friends from within the government) even when the data that they were requesting was already available on the portal, simply because they were not aware that the portal existed (ibid.). For the local government, their task was to make information available; they did not perceive engaging with users and increasing their understanding of technical documents as a part of that process. However, this is a result of the programme design rather than the implementation in Bohol. The national government agency that launched the initiative (Department of Interior and Local Government (DILG)), designed the FDP primarily as a data and information disclosure mechanism, without closing the feedback loop. Hence, the objective of the initiative is largely intended to make the data available, not necessarily to encourage citizens to engage with the government. Nevertheless, even at the DILG level, there has been a lack of initiative to educate users, and this was generally true for the rest of the country at the time when FDP was implemented. Most of the data literacy trainings if and when they happened, similarly to the case of Bohol - were initiated by actors outside of the government. The capacity building training launched in Bohol by Step Up Consulting resulted in a number of positive outcomes. Regular mentoring activities increased the knowledge and skills of the participants to use data in their advocacy and development work, including advocating for better use of the local government's disaster risk reduction and management funds. This was particularly relevant as the province suffered a major environmental disaster shortly before the training was conducted - a 7.2 magnitude earthquake that resulted in damage to the local economy worth USD 47 million. 


\section{Banda Aceh: From Freedom of Information to open data}

Banda Aceh is the capital and the largest city in the province of Aceh, located in the north-western tip of Indonesia. Home to approximately 248727 people, the majority of whom are Muslim, the city is recovering from a devastating tsunami that claimed lives and property approximately ten years ago. The city has been the centre of conflict for many years, in recent times between the Indonesian national government and secessionist local forces. Nevertheless, the post-tsunami mobilisation seemed to improve national and local alliances and the city has been relatively peaceful since. To date, Banda Aceh enjoys a level of autonomy, implementing Sharia law strictly within its boundaries.

In 2008, the Indonesian government introduced the national Freedom of Information Act (FOIA), providing legal guarantee for citizens on how to access information held by government institutions at the national, regional and district levels through various request channels. The city government of Banda Aceh introduced a wide range of policy measures to promote unrestricted access to information at the city and sub-district levels. The government of Banda Aceh is considered as one of the most responsive to citizen information requests - the Information and Documentation Management Officers (PPID) ensure that the information provided by authorities is not only compliant with the law, but also satisfactorily fulfils the needs of citizens. The city of Banda Aceh ranked first out of 23 municipalities and districts at the provincial FOI Awards in $2014^{1}$ and in 2015. ${ }^{2}$ Despite this recognition, the uptake of FOI in Banda Aceh is considered as low. PPIDs only received a total of 40 FOI requests, submitted either online or offline throughout 2014. They responded to 34 FOI requests and provided citizens with information such as school profiles, teacher profiles, population data, and the results of the general election. A total of six FOI requests were denied due to the data not being available. The figures for 2015 were similar the city government received 36 requests and almost all were resolved.

The FOI/OD Banda Aceh project was introduced in 2014 with the aim of minimising the information gaps between the government and citizens by harnessing the potential of open government data. Implemented by the World Wide Web Foundation's Open Data Lab Jakarta and funded by USAID under its Kinerja project from October to December 2014, the FOI/OD Banda Aceh project complemented the existing FOI efforts to increase the supply, demand and use of public information. Thus, the project encouraged the city government to practise proactive data disclosure, while simultaneously building capacities of Civil Society Organisations (CSOs) to make meaningful use of this data. The initiative had high political support with a desire to demonstrate its progression towards democracy embracing the information technology.

1 http://perhubungan.bandaacehkota.go.id/v3/pemko-banda-aceh-terima-anugerah-kip-2014/

2 http://www.lintasnasional.com/2015/12/10/komisi-informasi-aceh-gelar-anugerah-

keterbukaan-informasi-publik/ 
The first phase of the project supported the education agency in disclosing 17 datasets requested by CSOs. Some of these datasets included school profiles, teacher profiles, school budget, and online student admission. The project resulted in the launch and operationalisation of the Banda Aceh open data portal ${ }^{3}$ with two more departments participating in proactive disclosure other than the education agency (e.g. transportation and communication agencies). The project trained 27 civil servants on open data and proactive disclosure and 25 representatives from 19 CSOs in accessing, understanding, and using the open data published by the education agency. This process was replicated for the health and transportation datasets. The number of data downloads from the portal exceeded the number of FOIA requests by more than 700 . The ease of accessing government data through the portal in comparison to filing paper requests was a significant factor contributing to its popularity.

However, only a few departments participated in the open data portal. In the meeting with Dishubkominfo, the Badan Perencana Pembangunan Daerah (Bappeda) planning agency, and the Sekda (city secretary), the city mayor of Banda Aceh expressed the need to institutionalise proactive disclosure in the city through a mayor's legislation and a concrete action plan. This proposal was seconded by CSOs headed by Gerak Aceh, an anti-corruption nongovernmental organisation. An initial discussion of the draft regulation was completed in the early part of 2016 and promulgated into a mayor's regulation before the mayor stepped down from her post, having formulated a roadmap for proactive information disclosure in the city.

Similar to the Bohol case, national imperatives, alongside demands for better access to data from civil society groups, facilitated the data disclosure process and made it more efficient. What is unique about the Banda Aceh case study is the strong buy-in from the information and communication agency in pushing for the data disclosure agenda that culminated in the passage of local policies to support the requirement for data disclosure from other government agencies.

\section{From global to local: drivers and enablers of data disclosure}

What were the drivers that enabled the process of localising the open government and open data agenda? Looking at the case studies of Bohol and Banda Aceh, the following key ingredients emerge: leadership, civil society, legislation, data literacy and approach.

First, political commitment is key. Sub-national spaces led by government leaders who perceive transparency and accountability as important ingredients in improving public service delivery and have the buy-in of key department officials from critical agencies have a higher likelihood of success.

3 http://data.bandaacehkota.go.id/ 
In Banda Aceh, the city mayor and the officials from the planning agency and the information, communication and technology office were the main initiators in pushing for greater transparency through open data. However, scaling the pilot interventions that were initially started in two departments was met by considerable resistance from several government officials who were looking for a legal basis in the practice of open data. Without an enabling national law on open data, local partners drafted a mayor's regulation on data management that contained provisions on open data and proactive disclosure. Without the regulation, increasing the number of departments covered and the number of datasets published would have been an arduous task. Surely, this regulation would not have been possible without the strong push from the departments, and the commitment of the city mayor who issued them.

Second, a vibrant civil society is critical in pushing for and sustaining open government initiatives, including open data. Without civil society participation, such as advocates, watchdogs, initiators for better transparency, accountability, and openness, open government and open data processes might become supplyled and irrelevant. Therefore, civil society should have the capacity to engage proactively with the government. The relative power of civil society to exert influence on local government leadership is crucial. In the case of Bohol, civil society was considered as a governance partner, largely brought about by policy requirements that mandate civil society engagement and collaboration on key development issues, especially during the time when Bohol was considered one of the 20 poorest provinces in the country. In Banda Aceh, the relationship was initially more antagonistic, as the primary mover of the transparency initiative from the civil society side was an anti-corruption NGO. Open Government Partnership and its principle of co-creation require a thriving civil society. However, it might not be the case in most sub-national governments. For instance, in the Philippines, while procurement legislation requires that contracting activities are observed by civil society organisations, in some jurisdictions, there are no qualified civil society observers. Here, co-creating government plans may not be feasible. The reason why it was successful in both, Bohol and Banda Aceh, was the long tradition of civil society participation in local governance, conditioned by the presence of local actors working on specific issues and interacting regularly with the government. This is not necessarily true across the whole of Indonesia and the Philippines.

Third, building local capacity within the government and civil society groups is key. In the case of open data, this is where data literacy that shows concrete results is fundamental in using open data to promote better governance. Raising awareness of the importance of proactive disclosure mechanisms and inciting stakeholders' appreciation of the power of data is an important initial step. Once the value of data is clear to data suppliers and users, engaging them in skillbuilding activities will be easier and faster. However, skill-building activities should be able to demonstrate concrete results to sustain interest in data-driven 
approaches. What the data reveals is important, but what can be done with it is critical in generating the value out of open data. Often, data trainings end with generating insights and revealing information that was unavailable without access to datasets. Thus, data trainings should lead to concrete actions that governments and citizens can act on.

Finally, open government and open data can work if the initiative is latched onto problem-solving exercises that push for better delivery of public services. Problem-driven data approaches cultivate and incentivise data use. Engaging the users to begin identifying the problem that different stakeholders are passionate about contributes to more effective implementation of data-driven solutions. In most cases, these are problems that affect people's daily lives, such as a high malnutrition rate in children, or finding a locally made product to promote and sell. Having identified the problem to solve, we ask the following questions: what data do we need to be able to find solutions to these problems and how can we get it? This approach helps ensure that when the requested government data will be made available, it will be accessed and used. It also ensures the government of the importance of disclosing the data for solving problems that governments ought to address.

Creating a 'culture of data' requires a conscious choice to base decisions on data only; this includes analysing the political implications of disclosing or not disclosing data. Data openness levels the playing field in terms of exerting power in policy-making as the same datasets can become the basis for contestation.

\section{Challenges in localising the global agenda}

Localising the global agenda on open data has many challenges. The case studies in this chapter demonstrated the following challenges: the lack of consultations with sub-national governments where national commitments were made; lack of a legal and institutional framework to guide the efforts for localisation; unrealistic expectations of the quality of civil society organisations at the subnational level; and political transitions affecting the sustainability of reforms.

First, global commitments on open government and open data are discussed at the global and national levels, without necessarily conducting wider consultations with sub-national governments. The Open Government Partnership is an initiative of national governments that has been cascaded to sub-national platforms only recently. The awareness that sub-national leaders have of these commitments is uneven, with more proactive leaders and those with strong participation in national discussions being relatively more aware. In both Bohol and Banda Aceh, the open data awareness of local leaders was externally driven by researchers and international organisations. The receptiveness of local leaders to this external push was critical for the agenda to succeed locally.

Another barrier is the lack of a legal and institutional framework to localise global commitments. In Indonesia, open data initiatives are hampered by the 
absence of a national legal framework that requires proactive data disclosure in open formats. In the Philippines, there is specific operational guidance on how local governments undertake data disclosure, yet it does not contain open data provisions. Furthermore, there is a lack of policy mechanisms where local governments can contribute to open government besides the Full Disclosure Policy requirement. Given that there is no 'localisation' design, most of these initiatives when cascaded to sub-national level depend on the strong political commitment of local leaders, the creativity of the local bureaucracy, or the push of civil society organisations.

Third, political transitions pose a significant risk to the sustainability of open government reforms. To ensure that open data reforms are immune to political transition remains a challenge, especially when these are not institutionalised. In Bohol, this problem was mitigated due to the re-election of the previous governor for his third term. However, due to the three-term limit, the transition will occur shortly. In Banda Aceh, several stakeholders were apprehensive because of the upcoming elections during the key phase of implementing open data initiatives. In a strategic move to preserve open data practices in the city, different stakeholders from inside and outside of the government pushed for the issuance of a mayor's regulation. This was a critical move as the mayor who supported the initiative and issued the regulation lost the elections. Nevertheless, his open data regulation is still in effect.

Finally, technology-enabled interventions require investments in skills, infrastructure, and enabling conditions. In decentralised contexts where local revenue is insufficient, this may be deprioritised in favour of social and economic programmes, besides the fact that these may be beyond the capacity of poor, small local governments to invest in. Hence, as indicated in the cases of Bohol and Banda Aceh, open data initiatives happened because of having significant external donor support. In Banda Aceh, donor support enabled investment in capacity building for suppliers and users of data. In Bohol, local government capacity was already high, partially owing to donor-funded governance programmes focused on building bureaucratic capacity. Nevertheless, investment in improving civil society capacity to work with data was provided by external donors.

\section{Conclusion}

For open data to result in more transparent and accountable governance at the sub-national level, there is a need to ensure that the local governments are able to disclose key information about how the government is carrying out its mandate, and that citizens have the capacity to engage and use this information to scrutinise government functioning, help identify solutions to local problems, and promote a conversation to close the feedback loop in service delivery. Developing a process that brings together different stakeholders to define and agree on common goals and use data is a crucial investment in time and resources. 
The results of this research are important, especially because the Open Government Partnership has been extending the implementation of national pilots of the OGP process, including the open data pilots. This chapter could help inform how sub-national pilots are structured, implemented or monitored. Nevertheless, the results of this research are limited only to the cases covered in this study. Future investigation is needed to analyse cases in different countries, particularly those where the open data agenda is largely defined by national governments.

This chapter offers the following key recommendations in terms of localising open government and open data commitments:

a. Engage in local consultations with local government units. National commitments that affect local governments need to be a product of consultations with local leaders. National governments need to improve communication with the local leaders as high-level political support is key in advancing open data initiatives. Incentives to participate in open data initiatives need to be clearly communicated to the local leaders; for instance, rewards for excelling in the initiative or finding solutions to long-standing problems faced by citizens and their communities.

b. Ensure foundational legal basis for proactive data disclosure and the implementation of open data initiatives. The absence of legal basis poses a significant challenge for local governments to exact commitment from local agencies. Having a legal framework can institutionalise open data initiatives and insulate these against changes in leadership.

c. Provide avenues for citizen engagement through selected representatives (with civil society organisations acting as intermediaries).

d. Invest in local capacity for data suppliers and data users. The focus of capacity development initiatives depends on the initial needs assessment. In some cases, this will require providing a basic technical infrastructure along with technical training. In others, it will work to improve the ability of users to access and use the disclosed government data.

\section{REFERENCES}

Asian Development Bank (2017) Localizing Global Agendas Report on the Joint Learning event of the Governance Thematic Group and the Development Partners Network on Decentralization and Local Governance. Manila: ADB

Cañares M (2014) Opening the local: Full disclosure policy and its impact on local governments in the Philippines. Paper presented at ICEGOV '14: Proceedings of the 8th International Conference on Theory and Practice of Electronic Governance, Guimaraes, Portugal, October 2014. pp. 89-98. http://dl.acm.org/citation.cfm?id=2691214

Cañares M, Marcial D \& Narca M (2016) Enhancing citizen engagement with open government data: The case of local governments in the Philippines. The Journal of Community Informatics 12(2): 69-98. http://www.ci-journal.net/index.php/ciej/article/ view/1256/1208 
Cañares M \& Shekhar S (2016) Open data and sub-national governments: Lessons from developing countries. The Journal of Community Informatics 12(2): 99-119. http://www. ci-journal.net/index.php/ciej/article/view/1260/1209

Escobar A (2001) Culture sits in places: Reflections on globalism and subaltern strategies of localization. Political Geography 20(2): 139-174

Fukuoka Y (2015) Who brought down the dictator? A critical reassessment of so-called 'people power' revolutions in the Philippines and Indonesia. The Pacific Review 28(3): 411-433. DOI: 10.1080/09512748.2015.1011212

Gaventa J (2006) Finding the spaces for change: A power analysis. IDS Bulletin 37(6): 23-33

Heeks R (2004) Causes of e-government success and failure: Factor model. Institute for Development Policy and Management. Manchester: University of Manchester

Hines C (2000) Localization: A Global Manifesto. London, New York: Earthscan

Mangahas M (2014) Independent Reporting Mechanism: Philippines Progress Report 20112013. Open Government Partnership and the Philippine Center for Investigative Journalism. https://www.opengovpartnership.org/wp-content/uploads/2019/07/ IRMReport_Phillipines_100813c.pdf

Open Government Partnership (2015) Subnational governments and the open government partnership: Issues and Options Paper. Unpublished document.

Open Government Partnership (2016a) Open by default, policy by the people, accountability for results. Washington, DC: OGP

Open Government Partnership (2016b) Open Government Subnational Declaration: Paris-France 2016. Washington, DC: OGP

Peixoto T \& Fox J (2016) When does ICT-enabled citizen voice lead to government responsiveness? World Development Report. Unpublished Background Paper. http:// hdl.handle.net/10986/23650

Sidel J (2005) Bossism and democracy in the Philippines, Thailand, and Indonesia: Towards an alternative framework for the study of 'local strongmen'. In:

J Harriss, K Stokke \& O Törnquist (eds) Politicising Democracy: The New Local Politics of Democratisation. UK: Palgrave Macmillan. pp. 51-74

United Nations (2014) The Road to Dignity by 2030: Ending Poverty, transforming all lives and protecting the planet. Synthesis Report of the Secretary General on the Post-2015 Agenda.http://www.un.org/disabilities/documents/reports/SG_Synthesis_Report_ Road_to_Dignity_by_2030.pdf

Voisey H \& O'Riordan T (2001) Globalization and localization. In: T O’Riordan (ed.) Globalism, Localism, and Identity: Fresh perspectives on the transition to sustainability. London, New York: Earthscan. pp.25-42 